\title{
Awareness and Practice of Pre-travel Vaccination Among International Travelers Departing from Addis Ababa Bole International Airport
}

\author{
Oluwatosin Samson Jegede ${ }^{1 *}$, Ahmed Ali $^{2}$, Wondimu Ayele ${ }^{2}$ \\ ${ }^{1}$ Department of Community Medicine, LAUTECH Teaching Hospital, Ogbomoso, Nigeria \\ ${ }^{2}$ Department of Preventive Medicine, School of Public Health, College of Health Sciences, Addis Ababa University, \\ Ethiopia
}

Corresponding Author: Oluwatosin Samson Jegede, MPH, Department of Community Medicine, LAUTECH Teaching Hospital, Ogbomoso, Nigeria. Tel: +234-8035738878, Email: dr.jegzy1@gmail.com

Received November 23, 2019; Accepted April 20, 2020; Online Published April 30, 2020

\begin{abstract}
Introduction: International travelers are exposed to health risks and may transmit infections before, during, or after travel. Travelers are expected to take vaccinations prior to travel. The current study assessed the factors associated with the practice of pre-travel vaccination among travelers departing through Addis Ababa Bole International Airport after their stay in Ethiopia.

Methods: This cross-sectional study was conducted among 670 international travelers. A multistage sampling technique was used to ensure the representativeness of travel destinations. Awareness and practice of pre-travel vaccination were assessed using a self-administered questionnaire distributed at the departure lounges of the airport. Logistic regression analysis was used to identify significant factors (at $P<0.05)$ associated with pre-travel vaccination status. Median age was reported with its interquartile range $(I Q R)$.

Results: A total of 639 questionnaires were analyzed given a response rate of 95.4\%. The median age of participants was 34 years (IQR 28-41). Five hundred and eighty travelers (90.8\%) were aware of pre-travel vaccinations, $531(83.1 \%)$ took vaccinations, and 185 (29.0\%) had their vaccination cards checked upon arrival in Ethiopia. The vaccination rate of the three recommended vaccines for all travelers were yellow fever (72.5\%); diphtheria, pertussis, and tetanus (DPT) (21.4\%); and influenza (10.8\%). Age, marital status, religion, and having vaccination cards checked on previous trips were associated with vaccination status at $P$ values of $0.047,0.035,<0.001$, and 0.002 , respectively.

Conclusion: The uptake of recommended vaccinations for all travelers, especially DPT and influenza was low. It is pertinent for border health staff to scale up vaccination card inspection at points of entry.

Keywords: Airports, Border Health, International Travelers, Pre-travel, Vaccination, Yellow Fever
\end{abstract}

Citation: Jegede OS, Ali A, Ayele W. Awareness and practice of pre-travel vaccination among international travelers departing from Addis Ababa bole international airport. Int J Travel Med Glob Health. 2020;8(2):58-65. doi:10.34172/ijtmgh.2020.10.

\section{Introduction}

Air transportation continues to increase over time, ${ }^{1}$ and international arrivals are forecasted to reach 1.8 billion by $2030 .^{2}$ International tourist arrivals at Africa and Europe grew at a higher than average rate in 2017 , with Africa having a $9 \%$ increment compared to $2016 .^{3}$ International travel exposes individuals to new cultural, psychological, physiological, and microbiological experiences ${ }^{4}$; travelers are thus exposed to a variety of health risks in unfamiliar environments. ${ }^{5}$

Although the medical profession and the travel industry can provide extensive help and sound advice, it continues to be the traveler's responsibility to seek information, understand the risks involved, and take the necessary precautions to protect their health while traveling. ${ }^{5}$ Travelers intending to visit a destination in any country should consult a travel medicine clinic or medical practitioner before their journey. This consultation should take place at least four to 8 weeks before the journey and preferably earlier if long-term travel or overseas work is envisaged. ${ }^{5}$ The traveler should be provided with a personal record of the vaccinations given using the international certificate for vaccination or prophylaxis (vaccination card). ${ }^{5}$ Travelers who are not aware of travel health services (such as pre-travel vaccination service) carry the risk of contracting or spreading infectious diseases.

Travel-related infections have been documented in some countries. For example, on the $4^{\text {th }}$ of November 2015, a 56-yearold German businessman was admitted to a hospital with acute renal failure following a cholera infection contracted during a

Copyright (C) 2020 The Author(s). This is an open-access article distributed under the terms of the Creative Commons Attribution License (http:// creativecommons.org/licenses/by/4.0), which permits unrestricted use, distribution, and reproduction in any medium, provided the original work is properly cited. 
three-day business trip to Manila, Philippines. ${ }^{6}$ In 2017, the Chinese Centers for Disease Control and Prevention (CDC) documented a total of eleven imported yellow fever (YF) cases among male Chinese workers who returned to Beijing from Luanda, Angola. ${ }^{7}$ Findings showed that none of the Chinese workers received a yellow fever vaccination prior to traveling to Angola. In another study, vaccinations against rabies, typhoid fever, Japanese encephalitis, and meningococcus were highly inadequate for adolescents traveling from Greece to endemic areas. ${ }^{8}$

Forty-seven countries in Africa and Central and South America are either endemic or have regions that are endemic for yellow fever. ${ }^{9}$ Ethiopia is one of the African countries with risk of yellow fever transmission. ${ }^{10}$ It also requires yellow fever vaccination for travelers arriving from countries with risk of yellow fever. ${ }^{10}$ The United States Centers for Disease Control and Prevention (CDC) and the World Health Organization (WHO) recommend the following vaccinations for travelers visiting Ethiopia: hepatitis A, hepatitis B, typhoid, cholera, yellow fever, rabies, meningitis, polio, MMR (measles, mumps and rubella), DPT (diphtheria, pertussis, and tetanus), chickenpox, pneumonia, and influenza. ${ }^{11}$ From this list, 3 vaccines (yellow fever, DPT, and influenza) are recommended for all travelers visiting Ethiopia. ${ }^{11,12}$

Studies on pre-travel healthcare seeking practices and pretravel vaccinations have been conducted in many developed countries $^{13-15}$ and a few developing countries ${ }^{16}$; however, such studies in Ethiopia are generally lacking. There is also a paucity of recent studies globally that compare the pre-travel vaccination status of travelers from developed countries with travelers from developing ones, leaving a gap that informed the internal comparison engaged in this study. Primary data was collected for this study in contrast to the secondary data (from travel clinics) used in previous studies. ${ }^{13-15}$

This study assessed the factors associated with the practice of pre-travel vaccination among travelers departing through Addis Ababa Bole International Airport after their stay in Ethiopia. The rate of vaccination card check at the points of entry of Addis Ababa Bole International Airport were also generated.

\section{Methods}

Study Design and Study Area

This cross-sectional study was conducted at Addis Ababa Bole International Airport. The airport is located in the Bole area, $6 \mathrm{~km}$ southeast of the city center and $65 \mathrm{~km}$ north of Debre Ziyet. Terminal II of the airport is dedicated to services for international travelers.

\section{Study Population}

The study population comprised international travelers departing from Ethiopia through the Addis Ababa Bole International Airport after their stay in Ethiopia.

\section{Inclusion Criteria}

International travelers 18 years and above were included in this study. The age limit was chosen because of the ethical need to acquire consent to participation from the parents/ guardians of minors who might not be traveling with them.

\section{Exclusion Criteria}

All passengers on transfer (Transfer passengers are those who change from one flight to another without leaving the airport during the process, while transit passengers are those who change from one flight to another or from one airline to another having had an overnight stay in the country) and those who could not read or write in either English or French (the two languages used for the data collection) were excluded. Ethiopian nationals were also excluded, because the vaccines ${ }^{11}$ are recommended for foreigners visiting Ethiopia.

\section{Sample Size Determination}

The minimum sample size was determined using the Leslie Fischer's formula with the following assumptions: 95\% confidence interval, $4 \%$ acceptable margin of error, and proportion ( $p$ ) of awareness about pre-travel vaccination was taken as $46 \% .{ }^{17}$ The calculated sample size (596) was increased by $10 \%$ to compensate for non-response or improperly completed questionnaires. The value obtained (662) was then rounded up to 670 international travelers.

\section{Sampling Technique}

The lists of the international flights and their daily flight schedule for the month of January 2019, the month preceding the study period, were obtained from the commercial travel section of the Operation Unit of Addis Ababa Bole International Airport. The total number of travelers per WHO region for the month of January was computed by the researchers based on the flight schedule and used to project the expected volume of travelers' for the month of February 2019. The departure flights were then grouped into six, based on their destinations and according to the regions of the $\mathrm{WHO}^{18}$ [African Region (AFRO), American Region (AMRO), South-East Asian Region (SEARO), European Region (EURO), Eastern Mediterranean Region (EMRO), and Western Pacific Region (WPRO)]. Traveler's country of residence was classified as developing or developed based on the Development Assistance Committee's (DAC) list of Official Development Assistance (ODA) recipients of the Organization for Economic Cooperation and Development (OECD) and the country classification system of the 2014 World Economic Situations and Prospects (WESP). ${ }^{19,20}$

A multistage sampling technique (involving stratified and simple random sampling) was used to select study participants. First, stratified random sampling and the proportion to population size approach were used to allocate the total sample size per WHO region to ensure the representativeness of travel destinations. The African region was further stratified into the West African, East African, Central African, and Southern African regions. Following stratification, daily data collection targets were set for the total sample size for each WHO region and the African sub-regions. Simple random sampling (using electronically generated random numbers) was then used to recruit subjects for the study according to 
the daily data collection targets and departure flight schedule.

Instrument for Data Collection and Data Collection Procedure A questionnaire adapted from related previous studies ${ }^{13,15,17}$ was used to collect relevant information. The questionnaire was prepared in the English language, translated to French, and then back translated to English to ensure consistency. The questionnaire was pre-tested prior to the commencement of the actual study, and items which were difficult to understand were reconstructed. Face validity was done by four experts who reviewed the questionnaire separately and answered on "how well the questionnaire measures the awareness and practice of pre-travel vaccination." The reliability was evaluated using Cronbach's alpha statistics. The value of Cronbach's alpha was $0.821(0.817,0.913)$ for all items in the questionnaire.

The questionnaires were distributed at the departure lounges (near the respective departure gates) before boarding. Twelve staff members (2 per WHO region) of the airport were recruited for data collection and trained for three days. Travelers' vaccination cards were checked to confirm vaccination status whenever respondents (travelers) gave consent. The data collection process took 4 weeks to complete.

\section{Data Management}

The data obtained was entered into a computer using EpiData version 3.1 and exported to Statistical Package for the Social Sciences (SPSS), version 25, for statistical analysis. All questionnaires noticed with errors or missing variables were rejected during data entry. Vaccination status was classified as "vaccinated" or "not vaccinated" (vaccinated travelers were those who took at least one of the three vaccines recommended for all travelers visiting Ethiopia, ${ }^{11,12}$ while those who did not receive any of the three vaccines were classified as not vaccinated). Bivariate analysis was done (using binary logistic regression) to assess the relationship between pre-travel vaccination status (dependent variable) and the independent variables. Before this step, variables too few to model were re-categorized to have an adequate sample size in each cell. Examples of such re-categorization were marital status, where the married were merged with divorced/separated/ widowed; and occupation, where casual workers were merged with part-time/full-time employment. The regions of Ethiopia were re-categorized as follows: Agrarian (Amhara, Tigray, and Oromia); Pastoralist (Somali, Afar, and Southern nations); Emerging (Gambela and Benishangul-Gumuz); and Cities (Addis, Harari and Dire Dawa). Only variables that were statistically significant during the bivariate analysis were included in the multivariable analysis. The level of statistical significance was set at $P<0.05$. The odds ratios (crude and adjusted) were presented with a $95 \%$ confidence interval.

\section{Results}

A total of 639 valid questionnaires, with a response rate of 95.4\%, were analyzed. The median age for all participants was 34 years with an interquartile range (IQR) of 28 to 41 . Four hundred and twenty-seven respondents (66.8\%) were males; 404 (63.2\%) were married; 221 (34.6\%) travelers had a postgraduate (masters, $\mathrm{PhD}$ or fellowship) level of education; 76 (12.2\%) travelers were unemployed/student/ trainee or retired; and 274 (42.9\%) had fixed-term/full-time employment. In terms of monthly income, 440 (68.9\%) earned less than or equal to 2000 US dollars monthly. Christianity accounted for the religion of $331(51.8 \%)$ travelers, while Islam and others (Jewish, Buddhism, Hinduism, and none) accounted for $201(31.5 \%)$ and 107 (16.7\%), respectively (Table 1).

Using the WHO classification of regions, this study found that $278(43.5 \%)$ travelers departing from Ethiopia were

Table 1. Socio-demographic Characteristics of International Travelers included in the Study

\begin{tabular}{|c|c|c|}
\hline Variable & Frequency $(n=639)$ & $\%$ \\
\hline \multicolumn{3}{|l|}{ Age groups } \\
\hline $18-29$ & 188 & 29.4 \\
\hline $30-39$ & 255 & 39.9 \\
\hline $40-49$ & 138 & 21.6 \\
\hline 50 and above & 58 & 9.1 \\
\hline \multicolumn{3}{|l|}{ Gender } \\
\hline Male & 427 & 66.8 \\
\hline Female & 212 & 33.2 \\
\hline \multicolumn{3}{|l|}{ Marital status } \\
\hline Single & 201 & 31.5 \\
\hline Married & 404 & 63.2 \\
\hline Divorced/separated/widowed/others & 34 & 5.3 \\
\hline \multicolumn{3}{|l|}{ Educational status } \\
\hline No formal & 6 & 0.9 \\
\hline Up to high school/Grade 1 to 12 & 171 & 26.8 \\
\hline Undergraduate/College & 241 & 37.7 \\
\hline Postgraduate (Masters/PhD/Fellowship) & 221 & 34.6 \\
\hline \multicolumn{3}{|l|}{ Occupation } \\
\hline Unemployed/student/trainee/retiree & 78 & 12.2 \\
\hline Self-employed/private business & 188 & 29.4 \\
\hline Casual worker & 99 & 15.5 \\
\hline Fixed-term/full-time employment & 274 & 42.9 \\
\hline \multicolumn{3}{|l|}{ Monthly income in USD } \\
\hline Less than or equal to 2000 & 440 & 68.9 \\
\hline Greater than 2000 & 199 & 31.1 \\
\hline \multicolumn{3}{|l|}{ Religion } \\
\hline Christianity (Orthodox, Protestant, Catholic) & 331 & 51.8 \\
\hline Islam & 201 & 31.5 \\
\hline Others (Judaism, Buddhism, Hinduism, None) & 107 & 16.7 \\
\hline \multicolumn{3}{|l|}{ WHO Region of Residence } \\
\hline AFRO & 278 & 43.5 \\
\hline EMRO & 119 & 18.6 \\
\hline EURO & 111 & 17.4 \\
\hline AMRO & 36 & 5.6 \\
\hline SEARO & 37 & 5.8 \\
\hline WPRO & 58 & 9.1 \\
\hline \multicolumn{3}{|l|}{ Area of residence } \\
\hline Urban & 560 & 87.6 \\
\hline Rural & 79 & 12.4 \\
\hline \multicolumn{3}{|l|}{ Country of residence } \\
\hline Developed & 194 & 30.4 \\
\hline Developing & 445 & 69.6 \\
\hline \multicolumn{3}{|l|}{ Region respondents are traveling to } \\
\hline AFRO & 310 & 48.5 \\
\hline EMRO & 111 & 17.4 \\
\hline EURO & 85 & 13.3 \\
\hline AMRO & 22 & 3.4 \\
\hline SEARO & 55 & 8.6 \\
\hline WPRO & 56 & 8.8 \\
\hline
\end{tabular}

Abbreviations: AFRO, African Region; EMRO, Eastern Mediterranean Region; EURO, European Region; AMRO, American Region; SEARO, South East Asia Region; WPRO, Western Pacific Region. 
from the African Region (AFRO) and 194 (30.4\%) resided in developed countries. The top three final destinations of travelers were the African region (48.5\%), the Eastern Mediterranean region (17.4), and the European region $(13.3 \%)$.

Of the total respondents, 468 (73.2\%) travelers stayed in Addis Ababa. Lengths of stay varied from less than 24 hours (58.5\%) to more than 4 weeks (11.9\%). The reasons why travelers came into Ethiopia included for work (15.6\%), tourism (10.5\%), and transit (52.9\%) among others (Table 2).

Of the total respondents, $580(90.8 \%)$ were aware of pretravel vaccinations and 531 (83.1\%) received pre-travel vaccinations before coming to Ethiopia. Two hundred and sixty-two (41.0\%) took pre-travel vaccinations because it was the right thing to do and $74(11.6 \%)$ because their employer recommended it. Some travelers did not take pre-travel vaccinations, because they did not find it to be important (5.2\%) or because they were not aware of it (4.7\%). Three hundred and three travelers (47.4\%) reported that their vaccination cards were checked at other international airports during previous trips; however, only 185 (29.0\%) had their vaccination cards checked upon arrival in Ethiopia. Though $426(66.7 \%)$ of the total respondents accepted to show interviewers their international card of vaccination, only 413 (64.6\%) eventually made their cards available for inspection (Table 3).

As displayed in Table 4, the three most received vaccinations were hepatitis A (34.3\%), hepatitis B (39.7\%), and yellow fever $(72.5 \%)$; chicken pox, shingles, and influenza vaccinations, received by $62(9.7 \%), 40(6.3 \%)$, and $69(10.8 \%)$ travelers,

Table 2. Travel History (within Ethiopia) of the International Travelers included in the Study

\begin{tabular}{lcc}
\hline Variable & Frequency $(\mathbf{n = 6 3 9 )}$ & \% \\
\hline Area Ethiopia traveler lived in/stayed & & \\
Amhara & 26 & 4.1 \\
Afar & 15 & 2.3 \\
Tigray & 22 & 3.4 \\
Somali & 24 & 3.8 \\
Oromia & 47 & 7.4 \\
Gambela & 10 & 1.6 \\
Benishangul-Gumuz & 1 & 0.2 \\
Southern Nations & 21 & 3.3 \\
Addis Ababa & 468 & 73.2 \\
Dire Dawa & 5 & 0.8 \\
Length of stay & & \\
$<24$ hours & 374 & 58.5 \\
1-7 days & 96 & 15.0 \\
1-4 weeks & 93 & 14.6 \\
1 to 6 months & 76 & 11.9 \\
Purpose of coming to Ethiopia & & \\
Study & 20 & 3.1 \\
Work/volunteer/humanitarian service & 121 & 18.9 \\
Visiting friends or relatives & 46 & 7.2 \\
Tourism & 67 & 10.5 \\
Conference/Meetings & 47 & 52.9 \\
Transit & 338 & \\
Have you been to Ethiopia before? & & 82.2 \\
Yes & 114 & \\
No & 525 & \\
\hline
\end{tabular}

respectively, were the three least received vaccinations.

Based on recommendations for all travelers visiting Ethiopia, $149(23.3 \%)$ of the total respondents were categorized as not vaccinated, while 490 (76.7\%) were vaccinated.

Multivariable analysis found that age, marital status, religion, and having vaccination cards checked in previous trips were all independently associated with vaccination status. Travelers aged 50 years and above were 5.372 times more likely to be vaccinated compared to those between 18 and 29 years at a $P$ value of 0.047 . Travelers in the married/ divorced/separated/widowed category were 2.346 times more likely to be vaccinated compared with travelers who were single at a $P$ value of 0.035 . Travelers with religions such as Judaism, Buddhism, Atheism, Hinduism, or no religion were 33.556 times more likely than Christians to be vaccinated at

Table 3. Awareness and Practice of Pre-travel Vaccination among International Travelers Included in the Study

\begin{tabular}{|c|c|c|}
\hline Variable & Frequency & $\%$ \\
\hline \multicolumn{3}{|l|}{ Aware of pre-travel vaccinations? $(n=639)$} \\
\hline Yes & 580 & 90.8 \\
\hline No & 59 & 9.2 \\
\hline \multicolumn{3}{|l|}{ Have you ever taken any pre-travel vaccination? $(n=639)$} \\
\hline Yes & 531 & 83.1 \\
\hline No & 108 & 16.9 \\
\hline \multicolumn{3}{|l|}{ Reason for taking pre-travel health vaccination $(n=531)$} \\
\hline It is the right thing to do & 262 & 41.0 \\
\hline My employer recommended it & 74 & 11.6 \\
\hline As part of requirements for visa & 118 & 18.5 \\
\hline To safeguard my health & 56 & 8.8 \\
\hline Others & 21 & 3.3 \\
\hline \multicolumn{3}{|l|}{ Reason for not taking pre-travel vaccination $(n=108)$} \\
\hline Financial reason/cost & 7 & 1.1 \\
\hline I did not find it important & 33 & 5.2 \\
\hline There was no time to do so/busy & 7 & 1.1 \\
\hline I am not aware about it & 30 & 4.7 \\
\hline To avoid side effects of vaccination & 2 & 0.3 \\
\hline I refused it & 1 & 0.2 \\
\hline Vaccines required were not available & 2 & 0.3 \\
\hline $\begin{array}{l}\text { Vaccines are contraindicated in pregnancy/in my health } \\
\text { condition }\end{array}$ & 6 & 0.9 \\
\hline Others & 20 & 3.1 \\
\hline \multicolumn{3}{|l|}{ Was your vaccination card checked on arrival? } \\
\hline Yes & 185 & 29.0 \\
\hline No & 454 & 71.0 \\
\hline \multicolumn{3}{|c|}{ Can you show us your international card of vaccination? $(n=639)$} \\
\hline Yes & 426 & 66.7 \\
\hline No & 141 & 22.1 \\
\hline I do not have one & 60 & 9.4 \\
\hline Vaccination card is not with me & 12 & 1.9 \\
\hline \multicolumn{3}{|l|}{ Yellow card seen } \\
\hline Shown & 413 & 64.6 \\
\hline Not shown & 226 & 35.4 \\
\hline
\end{tabular}


Table 4. Pre-travel Vaccination Rate of International Travelers included in the Study

\begin{tabular}{lcc}
\hline \multirow{2}{*}{ Variable } & \multicolumn{2}{c}{ Frequency $(\mathbf{N}=\mathbf{5 3 1})$} \\
\cline { 2 - 3 } Pre-travel vaccine & No $(\%)$ \\
Hepatitis A & $219(34.3)$ & $312(48.8)$ \\
Hepatitis B & $254(39.7)$ & $277(43.3)$ \\
Typhoid & $162(25.4)$ & $369(57.7)$ \\
Cholera & $138(21.6)$ & $393(61.5)$ \\
Yellow fever & $463(72.5)$ & $68(10.6)$ \\
\hline Rabies & $101(15.8)$ & $430(67.3)$ \\
Meningitis & $148(23.2)$ & $383(59.9)$ \\
\hline MMR & $125(19.6)$ & $406(63.5)$ \\
DPT & $137(21.4)$ & $394(61.7)$ \\
Chicken pox & $62(9.7)$ & $469(73.4)$ \\
\hline Shingles & $40(6.3)$ & $491(76.8)$ \\
Pneumonia & $71(11.1)$ & $460(72.0)$ \\
Influenza & $69(10.8)$ & $462(72.3)$ \\
Polio & $158(24.7)$ & $373(58.4)$ \\
\hline
\end{tabular}

a $P$ value $<0.001$. Travelers whose vaccination cards were not checked in previous trips were $68.4 \%$ times less likely to be vaccinated than travelers whose vaccination cards had been previously checked at a $P$ value of 0.002 (Table 5).

\section{Discussion}

The rates of pre-travel vaccination in this study were similar to the rates obtained in previous similar travel surveys. The most commonly reported pre-travel vaccinations were hepatitis $\mathrm{A}$, hepatitis B, tetanus, and typhoid. ${ }^{21,22}$ Influenza vaccination was reported by $10.8 \%$ of travelers compared to $<3 \%$ of travelers in a previous study. ${ }^{23}$ The relatively satisfactory level of documented yellow fever vaccination (72.5\%), the highest among the 14 vaccines studied, may indicate that travelers are more inclined to have the mandatory vaccinations.

When compared to the study of Toovey et al, in which $60 \%$ of respondents were carrying vaccination certificates and a further $21 \%$ of respondents admitted to having no vaccination certificate with them, ${ }^{17}$ the current study found that $64.6 \%$ of respondents were carrying vaccination cards, $1.9 \%$ reported that their vaccination cards were not with them, and $9.4 \%$ admitted to having no vaccination card.

Every 8 out of $10(83.1 \%)$ participants took pre-travel vaccinations. This finding was better than those of previous studies. For example, Maltezou et al assessed the preparedness of adolescents departing from Athens International Airport and found that only 15/68 (22\%) adolescents received pretravel vaccinations. ${ }^{8}$ This could be due to the fact that their study was conducted on a smaller sample (68 participants) compared with this index study which used 639 respondents. Also, the previous study was conducted among adolescents only, whereas the current study was conducted among adults aged 18 years and above. The finding from this study, however, is in keeping with the fact that bivariate analysis earlier established that travelers from developed countries were less likely to be vaccinated than travelers from developing countries (Table 5).
The reasons for not receiving pre-travel vaccinations were not different from the reasons reported by Heywood et al. They also found that lack of information was among the main reasons for travelers not getting vaccinated. ${ }^{24}$

Age and marital status were found to be associated with pre-travel vaccination status after controlling for the effects of other variables. The higher likelihood of travelers aged 50 years and above to be vaccinated contrasts with results of a study conducted among international travelers in Korea. They found that elderly travelers were less likely to be vaccinated. ${ }^{25}$ The reason for non-vaccination among the younger age group in this index study may be explained by their risky health behaviors, phobia for needles, or cost of vaccination.

Travelers following a religion other than Christianity or Islam had a very high vaccination status. This could be explained by the fact that Christians and Muslims might prefer to rely on divine protection when they travel rather than vaccinations. Other studies reviewed, however, did not find any association between vaccination status and religion.

Despite the association of previous vaccination card check with vaccination status, only $29.0 \%$ of travelers reported that their vaccination cards were checked upon arrival in Ethiopia. This finding was not different from what was obtained in some other developing countries. For example, vaccination card checks upon arrival in Tanzania were non-systematic. ${ }^{16}$ However, non-checking of vaccination cards at points of entry may lead to non-compliance of international travelers with international health regulations and the consequent risk of cross-border spread of diseases.

\section{Limitations}

Travelers who could not read or write in English or French were excluded, subjecting this study to selection bias. Selfreported information was used to assess pre-travel vaccination status, because the vaccination cards of some travelers were not available for verification, subjecting this study to recall bias.

\section{Conclusion}

This study revealed that the practice of pre-travel vaccination among international travelers is considerably low. Similarly, the uptake level of recommended vaccinations for all travelers, especially DPT and influenza vaccines, was low. Age, religion, marital status, and vaccination cards checked during a previous trip were all associated with pre-travel vaccination status.

The association of religion with vaccination status underscores the need for pre-travel vaccination counseling in churches and mosques as part of health education programs. It is also pertinent that the government of Ethiopia, through the Ministry of Health (Border Health), gear up vaccination card checks at the points of entry to the country. The Ministry of Foreign Affairs, through various Ethiopian embassies across the world, may need to make regulations to encourage travelers to get vaccinated with at least the three vaccines (yellow fever, DPT, and influenza) recommended for all travelers at the point of visa application. Researchers should 
Table 5. Factors Associated with Vaccination Status among International Travelers included in the Study

\begin{tabular}{|c|c|c|c|c|c|}
\hline Variables & No. $(\%)$ & COR $(95 \% \mathrm{CI})$ & $P$ Value & AOR $(95 \% \mathrm{CI})$ & $P$ Value \\
\hline \multicolumn{6}{|l|}{ Categorized age } \\
\hline 18 to 29 (Ref) & $188(29.4)$ & & & & \\
\hline 30 to 39 & 255 (39.9) & $1.196(0.781,1.833)$ & 0.410 & $1.158(0.523,2.565)$ & 0.718 \\
\hline 40 to 49 & $138(21.6)$ & $2.187(1.246,3.840)$ & 0.006 & $2.978(0.923,9.576)$ & 0.068 \\
\hline 50 and above & $58(9.1)$ & $1.505(0.740,3.062)$ & 0.259 & $5.372(1.021,28.256)$ & $0.047^{*}$ \\
\hline Single (Ref) & $201(31.5)$ & & & & \\
\hline Others (married/divorced/separated/widowed) & $438(68.5)$ & $1.733(1.184,2.536)$ & 0.005 & $2.346(1.062,5.182)$ & $0.035^{*}$ \\
\hline \multicolumn{6}{|l|}{ Educational status } \\
\hline Grade 12/high school/below (Ref) & $177(27.7)$ & & & & \\
\hline Undergraduate/College & $241(37.7)$ & $1.349(0.871,2.087)$ & 0.180 & $2.365(0.988,5.658)$ & 0.053 \\
\hline \multicolumn{6}{|l|}{ Occupational } \\
\hline Unemployed (student/trainee/retiree) (Ref) & $78(12.2)$ & & & & \\
\hline Self-employed/personal business & $188(29.4)$ & $2.859(1.621,5.044)$ & $<0.001$ & $2.412(0.742,7.836)$ & 0.143 \\
\hline Part-time or full-time employment & $373(58.4)$ & $3.070(1.836,5.134)$ & $<0.001$ & $1.971(0.704,5.524)$ & 0.197 \\
\hline \multicolumn{6}{|l|}{ Religion } \\
\hline Christianity (Ref) & $331(51.8)$ & & & & \\
\hline Islam & $201(31.5)$ & $0.909(0.613,1.348)$ & 0.635 & $1.132(0.484,2.651)$ & 0.774 \\
\hline Others (Judaism, Buddhism, Atheism, Hinduism, none) & $107(16.7)$ & $5.015(2.243,11.213)$ & $<0.001$ & $\begin{array}{c}33.556(4.093 \\
275.125)\end{array}$ & $0.001^{*}$ \\
\hline \multicolumn{6}{|l|}{ Country of residence } \\
\hline Developed (Ref) & $194(30.4)$ & & & & \\
\hline Developing & $445(69.6)$ & $1.659(1.130,2.436$ & 0.010 & $0.982(0.462,2.086)$ & 0.963 \\
\hline Pastoralist & $60(9.4)$ & $0.706(0.294,1.698)$ & 0.437 & $1.512(0.303,7.537)$ & 0.614 \\
\hline Emerging regions & $11(1.7)$ & $1.585(0.187,13.438)$ & 0.673 & $2.176(0.192,24.634)$ & 0.530 \\
\hline Cities & $473(74.0)$ & $0.446(0.240,0.829)$ & 0.011 & $1.015(0.294,3.507)$ & 0.982 \\
\hline \multicolumn{6}{|l|}{ Purpose in Ethiopia } \\
\hline Study/work/volunteer/humanitarian service (Ref) & $141(22.0)$ & & & & \\
\hline VFR/Tourism/conference/meetings & $160(25.1)$ & $0.609(0.324,1.145)$ & 0.124 & $1.393(0.443,4.379)$ & 0.570 \\
\hline Transit & $338(52.9)$ & $0.348(0.202,0.602)$ & $<0.001$ & $1.048(0.216,5.094)$ & 0.954 \\
\hline \multicolumn{6}{|l|}{ Duration of stay in Ethiopia } \\
\hline 0 to 24 hours (Ref) & $374(58.5)$ & & & & \\
\hline Greater than 24 hours to 6 months & $265(41.5)$ & $2.754(1.819,4.170)$ & $<0.001$ & $2.233(0.517,9.648)$ & 0.282 \\
\hline \multicolumn{6}{|l|}{ Traveler had vaccination card checked in previous travel } \\
\hline Yes (Ref) & $303(47.4)$ & & & & \\
\hline No & $336(52.6)$ & $0.211(0.136,0.325)$ & $<0.001$ & $0.316(0.152,0.660)$ & $0.002 *$ \\
\hline
\end{tabular}

Abbreviations: COR, crude odds ratio; AOR, adjusted odds ratio; VRF, Visiting friends and relatives.

consider studies to model the risk of cross-border disease transmission among international travelers categorized as not-vaccinated.

\section{Authors' Contributions}

OSJ conceived of the study, organized airport access, and supervised data collection. All authors analyzed and interpreted the data. All authors were major contributors in writing the manuscript. All authors read and approved the final manuscript.

\section{Conflicts of Interest Disclosures}

The authors declare that they have no conflicts of interest.

\section{Ethical Approval}

Ethical clearance for this study was obtained from the Ethical Review Committee of the Addis Ababa University, Ethiopia. The permission to carry out the study was obtained from the Airport Security Department through the Operation Manager of Addis Ababa Bole International Airport and also from the Head of the Ethiopian Food, Medicine, and Health 


\section{Research Highlights}

\section{What Is Already Known?}

1. Travelers may or may not acquire pre-travel vaccinations before they travel;

2. Travelers' age and travel for tourism influence pretravel vaccination; and

3. Non-vaccinated travelers are usually identified in travel clinics after their trip.

\section{What This Study Adds?}

1. This study is novel in Ethiopia and the first in 10 years in Africa. The most recently published similar study was conducted in Johannesburg in 2004;

2. This study used multistage sampling to ensure the representativeness of study participants which had not been done in previous similar studies;

3. The rate of vaccination card check at Ethiopian airport point of entry is low;

4. Non-vaccinated travelers were identified during their trip;

5. Country of residence (developed or developing countries) may influence pre-travel vaccination status; and

6. Religious belief and previous vaccination card check influence pre-travel vaccination status.

Care Administration and Control Authority (EFMHACA).

This study did not involve any physical/clinical examinations or investigations, and thus, the study did not pose any risk whatsoever to the participants (respondents). Written consent was obtained from each study participant before collecting information from them, and the respondents had the right to decline or withdraw from the study at any time. The participants were identified using serial numbers only to ensure confidentiality.

\section{Funding/Support}

This study was funded by the Postgraduate Academic Mobility for African Physician-Scientists (PAMAPS). The funding body had no role in the design of the study, the collection, analysis, and interpretation of data, or in the writing of the manuscript.

\section{Acknowledgments}

This research would not have been possible without the permission and support of the staff of Addis Ababa Bole International Airport, most especially Mr. Getanah (Operation Manager); Mr. Negussie, Mr. Addisu Nigatu, and Miss Falsika (of the Operations Department); Mr. Birhanu and Mr. Zeleke (of Customer Service); Mr. Alemseged, Mr. Wagayi, and Miss Makdes (of EFMHACA); Mr. Tesmegen (Border Health Staff Team Lead); and the Head of Airport Security Service.

\section{References}

1. World Health Organization (WHO). International Health Regulations 2005. 2nd ed. Geneva: WHO; 20058. doi:10.1177/146642407109100301.
2. World Tourism Organization (UNWTO). UNWTO Tour Highlights: 2016 Edition. Madrid, Spain: UNWTO; 2016. https://www.eunwto.org/doi/pdf/10.18111/9789284418145.

3. World Tourism Organization (UNWTO). UNWTO Tour Highlights: 2018 Edition. Madrid, Spain: UNWTO; 2018. https://www.eunwto.org/doi/pdf/10.18111/9789284419876.

4. El Sherbiny NA, Wafik GM. A study of travel medicine among National and international travellers in Egypt. J Public Health Epidemiol. 2011;3(7):324-328.

5. World Health Organization (WHO). International Travel and Health. Geneva: WHO; 2012. http://apps.who.int/bookorders/ MDIbookPDF/Book/18000079.pdf.

6. Slesak G, Fleck R, Jacob D, Grunow R, Schäfer J. Imported cholera with acute renal failure after a short business-trip to the Philippines, Germany, October 2015. Euro Surveill. 2016;21(1). doi:10.2807/1560-7917.es.2016.21.1.30099.

7. Schlagenhauf $P$, Chen LH. Yellow Fever importation to China a failure of pre- and post-travel control systems? Int J Infect Dis. 2017;60:91-92. doi:10.1016/j.ijid.2017.06.003.

8. Maltezou HC, Pavli A, Theodoridou K, et al. Preparedness of adolescents departing from Athens International Airport to Africa or Asia: a five-year airport-based prospective study. Travel Med Infect Dis. 2018;21:69-73. doi:10.1016/j.tmaid.2017.07.011.

9. World Health Organization (WHO). Yellow Fever. Geneva: WHO; 2019. http://www.who.int/news-room/fact-sheets/detail/yellowfever. Published 2018. Accessed August 31, 2018.

10. World Health Organization (WHO). Countries 1 with risk of yellow fever transmission 2 and countries requiring yellow fever vaccination. In: International Travel and Health. Geneva: WHO; 2018:1-4. http://www.who.int/ith/ITH_Annex_I.pdf.

11. Passport Health. Travel Vaccines and Advice for Ethiopia. Passport health website. https://www.passporthealthusa.com/destinationadvice/ethiopia/. Published 2018. Accessed November 25, 2018.

12. International Association for Medical Assistance to Travellers (IAMAT). Ethiopia: Routine Immunizations-IAMAT. https://www. iamat.org/country/ethiopia/risk/routine-immunizations. Published 2018. Accessed December 25, 2018.

13. Khan NM, Jentes ES, Brown C, et al. Pre-travel medical preparation of business and occupational travelers: an analysis of the Global TravEpiNet consortium, 2009 to 2012. J Occup Environ Med. 2016;58(1):76-82. doi:10.1097/jom.0000000000000602.

14. Stoney RJ, Jentes ES, Sotir MJ, et al. Pre-travel preparation of US travelers going abroad to provide humanitarian service, Global TravEpiNet 2009-2011. Am J Trop Med Hyg. 2014;90(3):553-559. doi:10.4269/ajtmh.13-0479.

15. Hagmann SHF, Rao SR, LaRocque RC, et al. Travel characteristics and pretravel health care among pregnant or breastfeeding US women preparing for international travel. Obstet Gynecol. 2017;130(6):1357-1365. doi:10.1097/aog.0000000000002360.

16. Schönenberger S, Hatz C, Bühler S. Unpredictable checks of yellow fever vaccination certificates upon arrival in Tanzania. J Travel Med. 2016;23(5). doi:10.1093/jtm/taw035.

17. Toovey S, Jamieson A, Holloway M. Travelers' knowledge, attitudes and practices on the prevention of infectious diseases: results from a study at Johannesburg International Airport. J Travel Med. 2004;11(1):16-22. doi:10.2310/7060.2004.13587.

18. World Health Organization (WHO). WHO Regional Offices. Geneva: WHO; 2018. http://www.who.int/About/Regions/En/. Published 2017. Accessed August 26, 2018.

19. Organisation for Economic Co-operation and Development (OECD). DAC List of ODA Recipients Effective for Reporting on 2012 and 2013 Flows. Paris, France: OECD; 2017. https://www. oecd.org/dac/financing-sustainable-development/developmentfinance-standards/DAC_List_ODA_Recipients2018to2020_flows_ En.pdf.

20. The Development Policy and Analysis Division (DPAD) of the, Department of Economic and Social Affairs of the United Nations Secretariat (UN/DESA). Country classification system. In: World 
Economic Situation and Prospects (WESP). New York; 2014:1-8.

21. Van Herck K, Van Damme P, Castelli F, et al. Knowledge, attitudes and practices in travel-related infectious diseases: the European airport survey. J Travel Med. 2004;11(1):3-8. doi:10.2310/7060.2004.13609.

22. Wilder-Smith A, Khairullah NS, Song JH, Chen CY, Torresi J. Travel health knowledge, attitudes and practices among Australasian travelers. J Travel Med. 2004;11(1):9-15. doi:10.2310/7060.2004.13600.

23. Heywood AE, Watkins RE, lamsirithaworn $S$, Nilvarangkul $K$, Maclntyre CR. A cross-sectional study of pre-travel health-seeking practices among travelers departing Sydney and Bangkok airports. BMC Public Health. 2012;12:321. doi:10.1186/1471-2458-12 321.

24. Heywood AE, Nothdurft $H$, Tessier D, et al. Pre-travel advice, attitudes and hepatitis $\mathrm{A}$ and $\mathrm{B}$ vaccination rates among travellers from seven countries. J Travel Med. 2016;24(1). doi:10.1093/jtm/ taw069.

25. Kwon HY, Lee $\mathrm{H}, \mathrm{Im} \mathrm{JH}$, et al. Determinants of compliance of travelers with vaccination and malaria prophylaxis at a travel clinic. J Korean Med Sci. 2019;34(33):e217. doi:10.3346/ jkms.2019.34.e217. 